\title{
WestVirginiaUniversity.
}

Department of Economics

Working Paper Series

\section{Role of Personality Style on \\ Bargaining Outcomes}

Bryan McCannon and John B. Stevens

Working Paper No. 15-22

This paper can be found at the College of Business and Economics

Working Paper Series homepage: 


\title{
Role of Personality Style on Bargaining Outcomes
}

\author{
Bryan C. McCannon \\ West Virginia University \& Center for Free Enterprise \\ corresponding author: bryan.c.mccannon@gmail.com \\ John B. Stevens \\ Saint Bonaventure University
}

21 May 2015

\begin{abstract}
Purpose: The motivation for the research is to identify whether personality traits can help explain the outcomes that arise in bargaining outcomes.

Design: Experiments with subjects playing the alternating-offers bargaining game are considered. Both full information and asymmetric information treatments are considered. Subjects also complete standardized Myers-Briggs Type Indicator assessments.

Findings: Personality type measurements are shown to help explain the opening offers, rejections, and resulting wealth in the negotiations. It is shown that interactions between the personality dimensions are important and that the interaction between personality and information play a key role in bargaining outcomes.
\end{abstract}

Research limitations/implications - The research utilizes laboratory experiments to generate data. This expands our understanding of individual level behaviour, but suffers from the limitation of not replicating realistic bargaining situations.

Practical Implications: The work should serve as a guide to organizations to identify traits of effective negotiators.

Social Implications: Bargaining is a central economic activity. Being able to identify the root of differences in outcomes from negotiations should be able to inform institutional design issues.

Originality/Value: Little work has been done connecting the rich literature in social psychology and management on personality to economic outcomes. The research on bargaining neglects to incorporate individual-level traits into the process. This research begins to bridge this gap and informs both bargaining theory as well as emphasizes the importance of personality in application. 


\section{Introduction}

Much emphasis in economic theory has been devoted to the study of bargaining. Two related problems in particular arise in contexts involving negotiations. There are numerous outcomes that can be rationalized and, consequently, coordination failure is a concern. Given the pervasiveness of negotiations, it is important to be able to effectively explain and predict the outcomes that arise.

Environmental factors, such as first-mover advantage and informational constraints, have been shown to influence outcomes in bargaining (see for examples Sonnegård (1996), Galinsky and Mussweiler (2001) and McCannon and Stevens (2014)). Reliance on institutional features presumes identical preferences and behaviors of decisionmaking. These features, though, only provide a partial explanation. Individual-level differences in behavior can also be expected to drive bargaining outcomes. The search, then, is to find measurable characteristics of the participants that explain bargaining behavior. We hypothesize that personality traits provide useful information. The fields of management and social psychology have a long history of developing metrics to measure individual's personality styles. We believe that personality traits of individuals contribute to the ability to predict outcomes of negotiations.

The research question addressed, then, is whether personality characteristics of the participants to the negotiation can explain behavior. To test this hypothesis alternating-offer bargaining game experiments are conducted. Subjects played both a full information and an asymmetric information treatment. Along with the collection of background information, the subjects also completed a personality-style inventory commonly employed in management education/training (Myers Briggs Type Indicator).

We find that along with economic environment measures (size of the endowment, firstmover advantage, and informational restrictions), personality factors help explain outcomes of the negotiations. Additionally, the size of an opening offer, along with the decision to accept or reject the offer, is shown to be driven, in part, by personality type.

Two interesting, specific results arise. First, while the four-dimensional personality styles are important, we provide evidence that the interaction between the dimensions is crucial. For example, while individuals who can be classified as "thinking" types seem to generate equivalent 
outcomes as those classified as "feeling" types, we show that "introvert-thinkers" do very well while "extrovert-thinkers" fare poorly, relative to the feeling types. While the thinking-feeling personality dimensions can be thought of as the degree of cognitive judgment and calculation being utilized, the introvert-extrovert dimension differentiates the orientation of the decisionmaker to others. Thus, the results indicate what is important is the interaction between orientations to others in strategic interactions along with the rationality of the judgments made. Hence, correlating strategic behavior with metrics of mental activity improve the predictive power in games with multiple equilibria.

Second, by putting the same subjects through a full information and asymmetric information treatment, we find that there are strong interaction effects between information and personality. Thus, one should not think of personality traits acting independently from the economic environment. To illustrate by extending the previous example, the success of the introvert-thinkers is shown to be concentrated in those games played with full information.

Ours is not the first to incorporate measurements of personality styles into experimental economics. The relationship between traits and decisionmaking has recently been advanced by Deck et al (2012). They consider group risk-taking, but find, though, that personality does not seem to affect how groups reach an agreement when making a risky decision. Considering, instead, experiments on game-theoretic behavior, Boone, De Brabander, and van Witteloostuijn (1999) study the Prisoner's Dilemma game. While in a one-shot game they conclude that individuals of different personalities behave similarly, the propensity to cooperate in finitelyrepeated games depends on personality types. While not directly a personality metric used in management, Gunnthorsdottir, McCabe and Smith (2002) use a "Machiavellian" instrument as an explanatory variable to predict behavior in the trust game. They find that while it is uncorrelated with trusting investments it does explain in part reciprocation. Ben-Nur, Kong, and Putterman (2004) conduct experiments analyzing gender differences in dictator game contributions. They find that there is correlation between personality styles and giving. Furthermore, Swope et al (2008) conduct numerous experiments and score individuals on MyersBriggs personality traits. They find some evidence that personality drives offers in ultimatum games, but not in dictator or trust games. Schmitt et al (2008) confirms these results in ultimatum games. Müller and Schwieren (2012) do find some evidence of an effect in the trust game. Finally, Perugini, Tan, and Zizzo (2010) study the interaction between gender, personality, and 
public goods contributions. They find no evidence amongst women, but some results arise correlating personality and contributions with men. While we present a similar analysis for the alternating-offers bargaining game, the previous research does not focus on multi-dimensional bargaining types or the relationship with them and informational constraints. Because we do consider these issues, we find stronger effects of personality traits on behavior. Also, the MBTI metric studied here, which will be discussed in Section II, focuses on measuring the decisionmaking process of an individual, which is directly applicable to strategic choices. With the exception of Swope et al (2008) and Schmitt et al (2008), the previous experimental research focuses on other metrics. ${ }^{1}$

While there is a healthy experimental literature on ultimatum games, some have previously investigated the alternating-offers game. Rubinstein's (1982) theoretical contribution was to illustrate that while there exists multiple equilibria, a unique subgame perfect outcome arises with impatient players. Regarding experimental contributions, Zwick and Chen (1999), Rapoport, Weg, and Felsenthal (1990), and Weg, Rapoport, and Felsenthal (1990) consider environments where there are asymmetric costs to disagreement allowing them to address the issue of fairness and punishment. Zwick, Rapoport, and Howard (1992) analyze a related game where bargaining can continue until an exogenous "break-down" occurs. Similarly, Weg and Zwick (1991) allow for both asymmetric costs and bargaining over surpluses and deficits. Zwick, Rapoport, and Weg (2000) investigate invariance failure in sequential bargaining. Goeree and Holt (2000) use differing fixed payments to differentiate noisy behavior from fairness consideration in a two-stage bargaining game. Cason and Reynolds (2005) conduct experiments that differ in the probability that the bargaining is allowed to go into a second round. The alternating-offers game is advantageous to study as it provides a potentially more realistic environment replicating actual negotiations. Also, its back-and-forth nature allows for more interaction between the participants allowing personality traits to be expressed.

In section 2 a description of personality styles and their measurement are discussed. The theoretical game studied is developed in section 3. Section 4 provides information on the experimental methods and section 5 presents the results. Section 6 concludes.

\footnotetext{
${ }^{1}$ The other popular test, known as the Big Five, can be thought of as focusing on behaviors such as "agreeableness" and "openness to experience", while the MBTI studied here emphasizes decisionmaking, which should be more applicable to game-theoretic, strategic reasoning.
} 


\section{Personality Styles}

Schmitt et al (2008) speculate that individuals "approach decision problems in different ways and that this can have meaningful impact on behavior" (p. 598). A variety of instruments have been used as a means of identifying personal traits to get at these differences. The MyersBriggs Type Indicator (MBTI) has its origin in the studies of Carl G. Jung, a Swiss psychologist (1875-1961). Jung argued that his patients displayed certain styles of thought and behavior which were repeated over time. In his work on psychological types, Jung outlined a framework for explaining preferences. The typology that followed has been the focus of considerable research regarding management, teamwork, and human behavior in general.

Isabel Briggs Myers (1980) developed the MBTI instrument in an effort to explain how personality influences human behavior. It is a tool commonly used in management education/training and has been modified by numerous researchers such as Champagne and Hogan (1979). Four preference dimensions emerged from this body of research. They include

1. How is information processed (sensing or intuition)?

2. How are decisions made (thinking or feeling)?

3. Where does one get/direct his/her energy (introverted or extroverted)?

4. How individuals organize and orient themselves to the outer world (judging or perceiving)?

These assessments measure the four dimensions of an individual's decisionmaking characteristics. Each personality dimension has certain features, strengths, weaknesses, and conditions that may benefit from the style associated with the attributes. See Briggs Myers (1980) and Kummerow et al (1997) for detailed discussion of the common behaviors of each type.

When deciding which instrument to use in their research, Swope et al (2008) indicated the primary motivation for using a tool like the MBTI, rather than alternative personality indicators, was its availability and popularity in the U.S. among industrial psychologist, as well as the general public. Also, MBTI tools focus on the components of the decision process, which makes them especially appropriate for studying game-theoretic choices. 
To describe the personal characteristics measured here, we begin with some background. Briggs Myers (1980) postulates that human behavior is not due to chance, but it "is in fact the logical result of a few basic, observable differences in mental functioning" (p. 1). The differences revolve around how people perceive and make judgments. Perceiving is the process of becoming aware of the world around us. It is seen in the context of judging, the way we come to a conclusion based on what we perceive. So perceiving is what we see (interpret) and judgment is what we do about it (making a decision).

Briggs Myers explains that perceiving is done in one of two ways; through our senses (using the five human senses) or the process of intuition, which is "by way of the unconscious incorporating of ideas or associations onto perceptions coming from the outside" (p. 2). What the brain conjures via a "hunch", or through "connecting the dots", can lead to a creative discovery. Since perception requires the attention of an individual, Briggs Myers suggests people are influenced by a preference for recognizing information through the senses, or by intuition (dimension 1).

When confronted with data, information, ideas and concepts an individual will reach a judgment based on the preference of thinking, or relying on their feelings (dimension 2). Thinking requires a process of logically coming to a conclusion based on what is seen and known. Feeling is considered the "appreciation...bestowing on something, a personal, subjective value" (p. 3).

Another way of displaying a preference for perceiving information, or making judgments and decisions, is by people demonstrating an interest in their "outer or inner worlds". This Briggs Myers considers as introversion or extroversion (dimension 3). The process of dwelling more with internal thoughts, ideas and unique reflection is seen as introversion. Being more involved in interactions with people and things around, outside the individual is considered extroversion. The preference for considering things internally, or interacting with others externally, is also related to what energizes people, and the need (or lack thereof) for a level of socialization.

The final dimension (4) is the difference between an expressed preference for judging, making a decision, or seeking additional information and taking more time, perceiving. There are times when people hesitate to make a decision, and in doing so are not as constrained by pressure. They take a more casual approach and are being more open-minded to an issue at hand 
(perceptive). When the desire for making a decision, moving on regarding an issue, is displayed an individual is seen as behaving more methodical, strategic, and planful (Kummerow et al, 1997).

In summary, people may be referred to as expressing a certain "type" based on the exercise of their mental activities. Individuals are not limited by these types, and can choose to behave in a manor opposite of how they are predisposed. Given the opportunity, though, to do what is more comfortable for an individual, in general, people will tend to exercise their preferred way of behaving (Briggs Myers, 1980). Table 1, then, provides a brief description of the personality styles.

[Insert Table 1 here.]

Since one's bargaining position in a negotiation can be favorably or unfavorably influenced by the level of preparation and knowledge of potential outcomes (Fisher and Ury, 1982), the understanding and influence of personal traits would seem appropriate (Galinsky and Mussweiler, 2001). The MBTI is an ideal tool for assessing bargaining outcomes. One may view the thinking-feeling dimension as a predisposition to making cognitive decisions. Their orientation to others, through the extrovert-introvert dimension, can be expected to reflect strategic thinking. The perceiving-judging dimension reflects the quality of the decisionmaking being made. Hence, game-theoretic, sophisticated decisionmaking can be assessed by this metric and is expected to improve explanations of outcomes.

Empirical examinations of personality exist in the management literature. In an analysis of job performance Barrick and Mount (1991) find a strong correlation between a conscientious personality style and high ratings across numerous occupations. Similarly, Judge, Heller, and Mount (2002) illustrate correlations between personality types and job satisfaction. The decision to gain on-the-job training is also correlated with trait measurements (Offerhaus, 2012). Entrepreneurs are found to exhibit different personality styles than managers (Zhao and Siebert, 2006), which is argued to drive the decision to engage in entrepreneurship. Mueller and Plug (2006) find that personality traits are correlated with higher earnings later in life and, specifically, gender differences in income. 
Measurements of personality, such as this, have been used outside of the management literature. Personalities of the members of a jury are shown to be correlated with likelihood of a guilty verdict and who is selected to be a jury foreperson (Clark et al, 2007). Types have been shown in the political science literature to be highly correlated with which party one affiliates with, political ideology, and whether or not someone affiliates with any political party (Gerber et al, 2012). In the field of public health personality styles have been shown to be correlated with unhealthy behaviors, such as being at risk for contracting HIV (Trobst et al, 2000) and drug use and excessive drinking of teenagers (Mendolia and Walker, 2013). See Freeman (1995) for a discussion of the importance of considering personality in economics. Evidence of the relationship between personality traits and behavior in strategic, economic decisions is lacking, which is the primary contribution of the work presented here.

We now turn to a straightforward analysis of the theoretical framework used in the experiment.

\section{Theoretical Model}

Consider a two-player, extensive-form game. Denote the agents as Player $A$ and Player $B$. Player $A$ has an endowment of 100 and chooses how much to give to Player $B$, keeping the residual for herself. Next, Player $B$ chooses whether to accept the division or reject it. If the offer is accepted the game ends. If it is rejected, Player $B$ makes a counteroffer of how much to receive, again leaving the residual to $A$. The rejection, though, destroys 10 so that $A$ 's wealth is only 90. Player A now has the choice to accept Player B's counteroffer or reject it. Each rejection reduces the wealth by 10 , but provides the rejector with the opportunity to make a new offer. The game ends with either an acceptance of an offer or ten rejections.

To formalize the description of the game, the payoff to Player $A$ in round $r$ (where $r$ is an odd number ${ }^{2}$ ) when he offers $a$ to $B$, who will not accept anything less than $b$, is

$$
\begin{aligned}
& \pi_{A, r}(a, b)=100-10(r-1)-a \\
& \pi_{B, r}(a, b)=a
\end{aligned}
$$

\footnotetext{
${ }^{2}$ For $r$ as an even number $a$ represents the amount requested by Player $B$ and $b$ is the most Player $A$ is willing to agree to.
} 
if $a \geq b$, and $\pi_{i, r}(a, b)=\prod_{i, r+1}$ if $a<b$ where $\prod_{i, r+1}$ is the continuation payoff. Assume $\prod_{i, 11}=0$.

The game has numerous Nash equilibrium. To illustrate suppose that Player B adopts a strategy of rejecting any amount less than $X>0$ in odd-numbered rounds and to propose $X$ in the even-numbered rounds. ${ }^{3}$ If Player $A$ responds by rejecting the proposals and offering any amount less than $X$, he will end up with a payoff of zero. Thus, A's decision is to choose in which round to make an offer of an amount at least as large as $X$ (or to accept the $X$ proposal). Obviously, he will not offer strictly more than $X$ in any round. Consequently, $A$ 's payoff is maximized by minimizing $r$, or rather, to make an offer of $X$ in round one. Thus, Player $A$ 's best response to $B$ 's strategy is to offer $a=X$ in round one (and in every other odd-numbered round). Given this strategy by Player $A$, the proposed strategy of Player $B$ is a best response. Thus, any division of the 100 can be rationalized.

Similar to Rubinstein (1982), though, the game has a unique subgame perfect Nash equilibrium. ${ }^{4}$ In round ten, there is only 10 remaining. Player $B$ 's best action is to request (and receive) all 10 . Given this, in round nine, Player $A$ must offer at least 10 to $B$. Thus, his best action is to divide the 20 in round nine evenly. In round eight, Player B must offer at least 10 to $A$ and, therefore, her best action is to offer 10 and keep 20. Continuing with this logic, Player $A$ offers 50 and keeps 50 in round one, which is accepted by Player $B .^{5}$

The final consideration in this theoretical environment is the issue of coordination failure. As illustrated, there are multiple equilibria in the game. All of them involve no rejections along the equilibrium path. Numerous experimental studies illustrate, though, that coordination failures exist. Effort is then devoted to identifying what are the properties of a game that facilitate or hinder successful coordination. For example, Schelling's (1960) seminal work on conflict argues that focal points are selected, while a healthy literature has developed pointing to the importance

\footnotetext{
${ }^{3}$ Of course, in late rounds the residual pot will be less than $X$. Thus, consider the strategy where in such rounds the full residual is demanded.

${ }^{4}$ Rubinstein (1982) considers a game where the endowment deteriorates by a proportion $1-\delta$ in each round. Consequently, his is an infinitely-repeated game and the unique subgame perfect Nash equilibrium involves Player A receiving more than $1 / 2$ of the endowment. Also, see Martins (2011) for a discussion of the theoretical environment.

${ }^{5}$ This result can be shown to hold more generally. Assuming endowment/penalty is an integer (here 100/10), if the ratio is an even number, then the unique subgame perfect Nash equilibrium is for each to receive endowment/2. Instead, if the ratio is an odd number, then the unique subgame perfect Nash equilibrium is for Player $A$ to receive [endowment + penalty] $/ 2$ and for Player $B$ to receive [endowment - penalty]/2. Hence, the ultimatum game where penalty = endowment is a special case.
} 
of a risk dominant equilibrium (Harsanyi and Selten, 1988; Kandori, Mailath and Rob, 1993; Young, 1993; McCannon, 2011).

An experimental investigation of an alternating-offers bargaining game allows us to address, empirically, these points. In a game with multiple equilibria, which one should be expected? Is subgame perfection an appropriate equilibria refinement to use? What drives coordination failures? And, specifically, can individual-level metrics of personality improve our understanding of these issues? It is to these questions that we now turn.

\section{Experimental Methods}

Experiments of the alternating-offer bargaining game described in the previous section were conducted. Students from a small, private university in upstate New York were used in the experiment. The students were recruited from undergraduate economics and management courses, along with MBA classes. A total of nine experimental sessions were conducted in November 2012 and March 2013. Sessions ranged from sixteen to thirty subjects. A total of 205 individuals participated. Background information was provided by the experimental subjects. Table 2 provides a brief description of the sample.

[Insert Table 2 here.]

Numerous previous experimental research has illustrated that gender, culture (Boarini, Laslier, and Robin, 2009), and other background characteristics correlate with behavior and, therefore, will be controlled for in the econometric analysis.

The alternating-offers bargaining game previously described was played. PowerPoint slides presented the rules of the game. Subjects were provided the opportunity to ask questions before the first round as well. Random pairings between the experimental subjects were made for each round. The game was played twice so that each individual had the opportunity to act as Player A and Player B. Offers, rejection decisions, and counteroffers were recorded.

Subjects sat next to each other in the room to engage in each negotiation. The subjects recorded their offers and rejection decisions on paper. Discussion and interaction was allowed and was not regulated. While anonymity is more typical in experiments, this design was selected 
to allow for personality to be expressed through the personal, social interactions. Previous work has shown the value of direct interaction between experimental subjects in eliciting social interactions in the laboratory. For example, Scharlemann, Eckel, Kacelnik, and Wilson (2000) in experimental trust games, show subjects photos of their partner either smiling or not. They illustrate that smiling elicits more cooperation.

Additionally, an asymmetric information version of the game was conducted as a second treatment. In it a stack of cards was used. On one-half of the cards the number 80 was written, while on the rest the number 120 was printed. Subjects were informed that the Player $A$ in the game would be shown at random one of the cards. The number printed represented the amount of endowment being negotiated over. Thus, in the second treatment Player $A$ was fully informed, while Player $B$ only knew the states and the probability distribution over them. Furthermore, subjects were informed that if an agreement is not reached within eight rejections, then both earn zero. The asymmetric information treatment was included to allow for the possibility of personality types differing in their relative success in various environments. The instructions were publicly announced, as well as posted on PowerPoint slides in the room. Two rounds of the asymmetric information treatment were played. Again, each round consisted of a new random pairing and subjects were ensured of having the opportunity to both act as the first-mover and the second-mover in the game.

In sessions with an odd number of subjects one was randomly selected to sit out in a round. With regards to monetary compensation, a lottery was conducted in each of the nine sessions for a cash prize. In sessions with about twenty subjects a cash prize of $\$ 20$ was awarded. For sessions with about thirty subjects a cash prize of $\$ 30$ was awarded (so that ex ante a similar expected payoff was possible). Subjects were informed that the probability of winning the cash prize depended on the number of "experimental dollars" they were able to obtain in the experiments. The probability a subject won the prize was simply determined by the number of experimental dollars earned divided by the total number of experimental dollars earned by all participants in the session. While quite modest, the cash prize was used to provide some financial benefit to doing well in the experiments.

Along with the experiments and completion of a background questionnaire, subjects took a personality-style inventory at the end of each session. Subjects were scored on the four dimensions previously discussed using the MBTI measurement tool created by Champagne and 
Hogan (1979). The assessment tool uses thirty-six questions to classify a subject in each of the four personality dimensions. Thus, each individual can be classified in one of sixteen possible personality mappings (from the binary outcomes in the four personality dimensions). On the assessment, $42.4 \%$ of the experimental subjects are introverts and $18.5 \%$ are intuiting types. ${ }^{6}$ Also, $64.9 \%$ are thinking types and $18.0 \%$ have perceiving personalities.

\section{Results}

First, the outcomes of the negotiations can be provided. Table 3 presents information on the behavior observed in the sessions.

[Insert Table 3 here.]

As one might expect, the Player A's in the sample offer less than one-half of the endowment. Interestingly, rejection rates are quite high. While over one-half of the opening offers are rejected, more than one-half of the counteroffers, given the opening offer is rejected, are also turned down. Hence, coordination failure is common. Consequently, over $13 \%$ of the wealth is destroyed through conflict in the negotiations. ${ }^{7}$ Ultimately, the first-movers obtain more of the pie.

From the experiments a number of variables can be created. First, Outcome represents the proportion of the endowment, Endowment, which is earned in a round of a session by an experimental subject. It is necessary to consider earnings as a proportion of the endowment since it varies across the observations. The number of rejected offers in a negotiation, Rejections, is also calculated. Furthermore, dummy variables capturing whether the negotiation occurred with asymmetric information, Asymmetric, and whether the individual acted as the first-mover, PlayerA, are created.

\footnotetext{
${ }^{6}$ Gerber et al (2012), studying a sample of over 12,000 adults, find that $48.3 \%$ of them are introverts. Thus, at least in this dimension, our subject pool is rather representative. Swope et al (2-008) report on members of the U.S. Naval Academy. In their sample type I, N, T, and P make up 43\%, 42\%, 75\%, and $40 \%$ of the subjects respectively. Briggs Myers (1980) herself records that for finance and commerce students $29.7 \%, 28.1 \%, 68.6 \%$, and $47.1 \%$ are of each type. Thus, our sample seems in line (at least regarding dimensions 1 and 3) with previous ones.

${ }^{7}$ This is consistent with the results in Zwick and Chen (1999) where opening offers ranged between $25 \%$ and $45 \%$ of the endowment. Similarly, rejection rates exceed $44 \%$.
} 
Economic theory would predict that the institutional features of the negotiation should affect the outcomes. Thus, one would expect variables such as the size of the endowment, having the first-mover advantage, and the information available to affect how much an individual receives in the bargaining game. In addition, characteristics of the individual, though, are hypothesized to affect the outcome. To investigate this, OLS regressions are estimated on the individual-level data using institutional features, demographic variables, and personality characteristics to explain the outcome of the bargaining experiments. Table 4 presents the results. A constant term and demographic controls are included in each specification, but not reported. ${ }^{8}$ Also, standard errors clustered by round of play are reported.

[Insert Table 4 here]

Institutional features of the negotiations affect the amount an individual earns. Interacting under asymmetric information reduces the proportion a person earns by over two percentage points. This represents $5.3 \%$ of the mean value of Outcome. Coinciding with the descriptive statistics of Table 3, Player As earn more. Finally, bargaining with a larger endowment leads to more wealth. This is noteworthy because Outcome is measured as the proportion of the endowment and Asymmetric differentiates the two treatments. Thus, while asymmetric information acts as a friction increasing conflict, it is less severe when negotiating over 120 and is more severe when bargaining over $80 .^{9}$

Column II includes dummy variables for each of the four personality dimensions: introverts $(I)$, intuiting types $(N)$, thinking types $(T)$, and perceiving types $(P)$, as compared to extroverts, sensing types, feeling types, and judging types respectively. There is statistically significant evidence that one of the personality traits, $P$, helps explain bargaining outcomes. This is confirmed by the substantial decrease in the AIC.

\footnotetext{
${ }^{8}$ The demographic controls included are dummy variables for being a first-year student, being an MBA student, gender, majoring in a business field (management, marketing, finance, accounting, business information systems, or "undecided" business), being a US citizen, and being a resident of New York, Ohio, Pennsylvania, New Jersey, or "other" state. With some sessions having an odd number of participants and a couple of subjects failing to provide complete background information, the individual-level data set includes 789 observations rather than $205 \times 4=820$.

${ }^{9}$ One may be concerned about the fact that Rejections has an endogenous component, namely that players choose whether to reject an offer and rejection by one's opponent in the negotiation is likely a function of the size of the opening offer. Dropping Rejections from the specifications do not alter the main findings presented.
} 
Column III includes interaction effects between personality dimensions. Quite a few of the categorizations significantly predict bargaining success. For example, while the thinkingfeeling distinction along with the introvert-extrovert dimension does not seem to matter (II) holding constant the other personality dimensions, the results in the third column illustrate that this is a misperception. Individuals who are introvert-thinkers do relatively well in the negotiations earning four percentage points more than the reference group (than the omitted group of extrovert-feelers). Extrovert-thinkers, though, perform poorly generating over three percentage points less in wealth. This explains why those assessed as thinkers, ignoring their personality in the introversion dimension, register as not affecting success in Column II.

Again, the goodness of fit measurements are improved from the specification without personality traits being controlled for: AIC stays low and the adjusted $\mathrm{R}^{2}$ improves. F-tests of the joint significance of the interaction terms and of all personality metrics reveal their joint significance as well (F-stats of 2.35 and 1.63 respectively with p-values $<0.1$ ). The statistical significance of personality type $P$ is lost, though. This may be due to the fact that perceiving types are relatively scarce. Separating them into subgroups, by considering interaction terms, simply suffers from a low number of observations. Hence, column IV drops them and, consequently, recovers $P$ 's significance.

The results in Table 4 illustrate that bargaining success depends on the information available. A reasonable question to ask, then, is whether personality traits affect conflict in bargaining differently with full information as compared to asymmetric information. Are there individual traits that perform relatively well without informational problems, but do poorly with the constraints (and vice versa)? Can knowledge of one's personality traits improve the ability to predict market failure with asymmetric information? To address this question interaction effects between personality types and information are considered. Table 5 presents the results. A constant term, all demographic controls, and the institutional features are included in each specification, but are not reported. Again, clustered standard errors are presented.

[Insert Table 5 here] 
As in Table 4, considering each personality dimension (holding constant the other three) provides little additional information. The success of type P individuals, illustrated in the previous table, is concentrated in the asymmetric information treatments.

The results in Column II illustrate that personality types interact differently in the two informational environments. To illustrate, consider type $\mathrm{N}$ and type $\mathrm{P}$ personality dimensions. Under full information an individual who is both type $\mathrm{N}$ and $\mathrm{P}$ does quite well bargaining, earning almost seven percentage points more of the pie (holding fixed the other two dimensions). If one is type $\mathrm{N}$ and not type $\mathrm{P}$ (or vice versa), then she does quite poorly (relative to someone who is neither type $\mathrm{N}$ nor $\mathrm{P}$ ). Under asymmetric information, though, NP people do relatively poor, while those who are type $\mathrm{P}$ but not type $\mathrm{N}$ do fantastically well.

The adjusted $\mathrm{R}^{2}$ is greater in Column II than in any prior specifications as well. Thus, not only does personality affect bargaining outcomes, but the directions of the successes depend on the information available.

While the previous analysis shows that information on personality traits improves the ability to explain outcomes of negotiations, the more specific questions of whether it can explain equilibrium selection, out-of-equilibrium outcomes, and legitimacy of subgame perfection can also be addressed. In other words, is it the case that introvert-thinkers, for example, are able to select an equilibrium more favorable to themselves, or do they expertly avoid coordination failure?

Table 6 summarizes the findings of additional econometric models. The three panels are differentiated by the variables used as the dependent variable. Equilibrium selection is identified by considering the opening offer, Opening, made by Player A since this, in equilibrium, identifies which outcome is to be selected. Subgame perfection is tested by considering a dummy variable, Split, which is equal to one if and only if the endowment is proposed to be divided equally between the two players. Finally, testing for out-of-equilibrium play is done by considering, as a dependent variable, the dummy variable Reject. Reject is equal to one if and only if the initial opening offer is rejected by second-mover.

The four columns of each panel replicate the set of independent variables used in Table 4, Columns I, II, and III, and Table 5, Column II. In the top and middle panel, only the sample of individuals in a round of a session randomly selected to be the first-mover, Player $A=1$, is considered. In the bottom panel, only the observations with the individual selected to be the 
second-mover are considered (Player $A=0$ ). Rather than present all econometric results, the personality trait control variables which are statistically significant (at at least the $10 \%$ level of significance) are listed. ${ }^{10}$

[Insert Table 6 here.]

The first panel illustrates that personality styles, again, help explain the bargaining process. Here, specifically, the opening offer is driven in part by differences in personality. Again, the two main results of the importance of multi-dimensionality and the interaction between personality and informational constraints are shown to be important. This is confirmed by the fact that the adjusted $\mathrm{R}^{2}$ increases as more personality trait controls are included. The first panel also provides some explanation of the results of the previous tables. For example, the lack of success of the type $\mathrm{N}$ individuals under full information (Table 5, Column II) comes from them making more generous opening offers.

The second panel considers, as a dependent variable, a dummy variable which is equal to one if and only if the first-mover offers fifty percent of the endowment. In the sample, this occurs $28.6 \%$ of the time. Once again, personality style and, specifically, the multi-dimensional measurements along with the interaction with information are shown to be important determinants of whether or not the subgame perfect equilibrium arises. ${ }^{11}$

Finally, the third panel considers the probability of the opening offer being rejected. As illustrated in section 2, in every equilibrium the first offer is accepted. Thus, we can address the question as to whether personality styles correlate with non-equilibrium events. Yet again it does. The McFadden $\mathrm{R}^{2}$ improves as the personality controls are included.

Interaction between the traits of the two parties to the negotiation in the pair-level data can be studied as well. Results confirm that the personality styles of the participants matter. Since no new insights arise, these additional results are excluded from the analysis presented here.

\footnotetext{
${ }^{10}$ In the top panel $N$ in specification 4.II and Asym NT in 5.II are statistically significant only when heteroskedasticrobust standard errors are calculated. This is also the case for $N$ in 4.II in the middle panel. Additionally, this is true for IP and Asym IN in 5.II of the bottom panel.

${ }^{11}$ In the full information treatment the rate of rejection when $50 \%$ of the endowment is offered drops to $5.8 \%$. Thus, in approximately $22 \%$ of the observations the subgame perfect equilibrium arose.
} 


\section{Conclusion}

Bargaining environments are associated with multiple equilibria and offer the possibility of coordination failure leading to inefficient outcomes. Institutional features, such as first-mover advantages, endowment sizes, and informational constraints, have been the focus of the economic analysis of bargaining. These provide partial explanations for bargaining outcomes that arise. Here we hypothesize that personality traits of the participants contribute to the prediction of equilibrium selection and coordination failures.

Experimental evidence presented confirms this belief. Success at the bargaining table can be explained in part by the measurable personality traits of the individual. Furthermore, the quality of the information interacts with personality traits to promote success. It is shown that some personality traits do a better job than others at selecting an equilibria more advantageous, while other personality traits are associated with out-of-equilibrium actions and inefficient outcomes.

These findings suggest that measurable characteristics, such as personality studied here, may be useful in practice as a way for an organization to perform better in negotiations. Also, though, theoretical investigations of bargaining may need to incorporate personality characteristics into frameworks along with institutional features, cognitive abilities, and adaptation/learning.

One potential shortcoming of the experimental design is that rather modest monetary compensation was provided. While it was enough to generate differing results, which may be a sufficient defense in of itself, one may be concerned that financial gain trades off with nonmonetary utility from play. How these two components of one's payoff are balanced may be type dependent so that results may be effected by this choice. If compensation was greater, then one would expect even stronger results, which would reinforce the results presented here. Since the primary goal of the experimental work was to illustrate that personality traits explain behavior, the adjustment to which personality types perform well under different levels of monetary compensation is beyond the scope of the current investigation. Additionally, the experimental design is rather unique in that subjects sat next to each other in the room and were free to communicate. While this was done to stimulate the expression of personality style in real-world bargaining, one may want to extend the work by considering whether personality traits are 
important in anonymous environment. Finally, only analysis from the individual-level data is presented here. As stated, the group-level data provides the same main conclusion, that personality traits of the negotiators can be used for equilibrium selection and out-of-equilibrium

forecasting, one may be interested in the extension to individuals, working together as a team on one side of the bargaining table, interacting to achieve the best outcome for the organization. In practice, it is common for negotiating teams to represent a firm. Thus, future work can focus on group outcomes with differing personality traits.

\section{References}

Barrick, M.R. and Mount, K. (1991), “The Big Five personality dimensions and job performance: A meta-analysis”, Personnel Psychology, Vol. 44 No. 1, pp. 1-26.

Ben-Nur, A., Kong, F., and Putterman, L. (2004), "Share and share alike? Gender-pairing, personality, and cognitive ability as determinants of giving”, Journal of Economic Psychology, Vol. 25, pp. 581-589.

Boarini, R., Laslier, J.-F., and Robin, S. (2009), "Interpersonal comparisons of utility in bargaining: evidence from a transcontinental ultimatum game", Theory and Decision, Vol. 67 No. 4, pp. 341-373.

Boone, C., De Brabander, B., and van Witteloostuijn, A. (1999), “The impact of personality on behavior in five prisoner's dilemma games", Journal of Economic Psychology, Vol. 20, pp. 343377.

Briggs Myers, I. (1980), Gifts Differing, Consulting Psychologists Press, Palo Alto.

Cason, T.N. and Reynolds, S.S. (2005), "Bounded rationality in laboratory bargaining", Economic Theory, Vol. 25 No. 3, pp. 553-574. 
Champagne, D.W. and Hogan, R.C. (1979), "Supervisory and managerial skills: a competency based training program for middle managers of educational systems."

Clark, J., Boccaccini, M.T., Caillouet, B., and Chaplin, W.F. (2007), "Big five personality traits, jury selection, and the case outcomes in real criminal and civil cases", Criminal Justice and Behavior, Vol. 34 No. 5, pp. 641-660.

Deck, C., Lee, J., Reyes, J., and Rosen, C. (2012), "Risk-taking behavior: an experimental analysis of individuals and dyads", Southern Economic Journal, Vol. 79 No. 2, pp. 277-299.

Fisher, R. and Udry, W. (1981), Getting to the Yes: Negotiating Agreement Without Giving In, Penguin Books, New York.

Freeman, K.B. (1995), “Utility interdependence when personality types interact”, International Journal of Social Economics, Vol. 22 No. 2, pp.4-18.

Galinsky, A.D. and Mussweiler, T. (2001), "First offers as anchors: the role of perspectivetaking and negotiator focus", Journal of Personality \& Social Psychology, Vol. 51, pp. 657-669.

Gerber A.S., Huber, G.A., Doherty, D., and Dowling, C.M. (2012), "Personality and the strength and direction of partisan identification", Political Behavior, Vol. 34, pp. 653-688.

Goeree, J.K. and Holt, C.A. (2000), “Asymmetric inequality aversion and noisy behavior in alternating-offer bargaining games", European Economic Review, Vol. 44, pp. 1079-1089.

Gunnthorsdottir, A., McCabe, K., and Smith, V. (2002), "Using the Machiavellianism instrument to predict trustworthiness in a bargaining game", Journal of Economic Psychology, Vol. 23 No. 1, pp. 49-66.

Harsanyi, J.C. and Selten, R. (1988), A General Theory of Equilibrium Selection in Games, MIT Press, Cambridge. 
Judge, T.A., Heller, D., and Mount, M.K. (2002), "Five-factor model of personality and job satisfaction: a meta-analysis", Journal of Applied Psychology, Vol. 87 No. 3, pp. 530-541.

Michihiro, K., Mailath, G.J., and Rob, R. (1993), "Learning, mutation, and long-run equilibria in games", Econometrica, Vol. 61 No. 1, pp. 29-56.

Kummerow, J.M., Berger, N.J., and Kirby, L.K. (1997), Work Types, Warner Books, New York.

Martins, A.P. (2007), Ideals in Sequential Bargaining Structure, International Journal of Social Economics, Vol. 34 No. 11, pp. 828-882.

McCannon, B.C. (2011), "Coordination between a sophisticated and fictitious player", Journal of Economics, Vol. 102 No. 3, pp. 263-273.

Mendolia, S. and Walker, I. (2013), "The effect of non-cognitive traits on health behaviours in adolescence”, IZA Discussion Paper No. 7301.

Mueller, G. and Plug, E. (2006), "Estimating the effect of personality on male and female earnings", Industrial and Labor Relations Review, Vol. 60 No. 1, pp. 3-22.

Müller, J. and Schwieren, C. (2012), "What can the big five personality factors contribute to small-scale economic behavior?”, Tinbergen Institute Discussion Paper No. 28.

Offerhaus, J. (2013), “The type to train? Impacts of personality characteristics on further training participation", German Socio-Economic Panel Study Working Paper No. 531.

Perugini, M., Tan, J.H. W., and Zizzo, D.J. (2010), "Which is the more predictable gender? Public good contribution and personality", Economic Issues, Vol. 15 No. 1, pp. 83-110. 
Rapoport, A., Weg, E., and Felsenthal, D.S. (1990), "Effects of fixed costs in two-person sequential bargaining”, Theory and Decision, Vol. 28 No. 1, pp. 47-71.

Rubinstein, A. (1982), "Perfect equilibria in a bargaining model”, Econometrica, Vol. 50 No. 1, pp. 97-109.

Scharlemann, J.P.W., Eckel, C.C., Kacelnik, A., and Wilson, R. (2001), "The value of a smile:

Game theory with a human face", Journal of Economic Psychology, Vol. 22 No. 5, pp. 617-640.

Schelling, T.C. (1960), The Strategy of Conflict, Harvard University Press, Cambridge.

Schmitt, P.M., Schupp, R., Swope, K.J., and Mayer, J. (2008), "Pre-commitment and personality: behavioral explanations in ultimatum games", Journal of Economic Behavior \& Organization, Vol. 66 No. 3-4, pp. 597-605.

Sonnegård, J. (1996), "Determination of first movers in sequential bargaining games: An experimental study", Journal of Economic Psychology, Vol. 17 No. 3, pp. 359-386.

Swope, K.J., Cadigan, J., Schmitt, P.M., and Schupp, R. (2008), "Personality preferences in laboratory economics experiments", Journal of Socio-Economics, Vol. 37, pp. 998-1009.

Trobst, K.K., Wiggins, J. S., Costa, P.T., Herbst, J. H., McCrae, R.R., and Masters, H.L. (2000), "Personality psychology and problem behaviors: HIV risk and the five-factor model", Journal of Personality, Vol. 68 No. 6, pp. 1233-1252.

Weg, E., Rapoport, A., and Felsenthal, D.S. (1990), “Two-person bargaining behavior in fixed discounting factors games with infinite horizons", Games and Economic Behavior, Vol. 2 No. 1, pp. 76-95.

Weg, E. and Zwick, R. (1991), “On the robustness of perfect equilibrium in fixed cost sequential bargaining under isomorphic transformation”, Economic Letters, Vol. 36 No. 1, pp. 21-24. 
Young, H.P. (1993), “The evolution of conventions”, Econometrica, Vol. 61 No. 1, pp. 57-84.

Zhao, H. and Siebert, S.E. (2006), "The big five personality dimensions and entrepreneurial status", Journal of Applied Psychology, Vol. 91 No. 2, pp. 259-271.

Zwick, R. and Chen, X.-P. (1999), "What price fairness? A bargaining study", Management Science, Vol. 45 No. 6, pp. 804-823.

Zwick, R., Rapoport,A., and Howard, J.C. (1992), “Two-person sequential bargaining behavior with exogenous breakdown", Theory and Decision, Vol. 32 No. 2), pp. 241-268.

Zwick, R., Rapoport,A., and Weg. E. (2000), "Invariance failure under subgame perfectness in sequential bargaining", Journal of Economic Psychology, Vol. 21 No. 5, pp. 517-544. 


\section{Table 1: Personality Dimensions}

Personality Style Brief Description

Introversion $(I) \quad$ seeks the inner world, prefers writing, learns best by reflection Extroversion $(E)$ tuned into the external environment, likes to communicate by talking, learns best by discussing

Intuiting $(N) \quad$ big picture, imaginative, future oriented

Sensing $(S)$ concerned with what is real, likes practical applications, present oriented

Thinking $(T)$

analytical, logical, impersonal objective truth

Feeling $(F)$

sympathetic, concerned with impact on people, compassionate

Perceiving $(P)$

spontaneous, casual, open-minded

Judging $(J)$

organized, systematic, methodical, sense of urgency 
Table 2: Subjects’ Backgrounds

$(N=205)$

\begin{tabular}{llllll}
\hline Characteristic & $\#$ & $(\%)$ & Characteristic & $\#$ & $(\%)$ \\
\hline Male & 125 & $(61.0 \%)$ & First-year student & 89 & $(43.4 \%)$ \\
U.S. citizen & 196 & $(95.6 \%)$ & MBA student & 50 & $(24.4 \%)$ \\
NY State resident & 138 & $(67.3 \%)$ & Business major & 188 & $(91.7 \%)$
\end{tabular}


Table 3: Description of the Negotiations

feature of the negotiation

average proportion

opening offer

rejected opening offers

rejected counteroffers

outcome for Player A

outcome for Player B

deadweight loss

$39.8 \%$ of the endowment

$54.3 \%$ of the offers

$55.7 \%$ of the counteroffers

$44.6 \%$ of the endowment

$41.7 \%$ of the endowment

$13.7 \%$ of the endowment 
Table 4: Bargaining Success and Personality

(dep. var. = Outcome; $N=789$ )

\begin{tabular}{|c|c|c|c|c|}
\hline & I & II & III & IV \\
\hline Endowment & $\begin{array}{l}0.001 * * * \\
(0.000)\end{array}$ & $\begin{array}{l}0.013 * * * \\
(0.000)\end{array}$ & $\begin{array}{l}0.001 * * * \\
(0.000)\end{array}$ & $\begin{array}{l}0.001 * * * \\
(0.000)\end{array}$ \\
\hline Asymmetric & $\begin{array}{l}-0.023 * * * \\
(0.007)\end{array}$ & $\begin{array}{l}-0.022 * * * \\
(0.008)\end{array}$ & $\begin{array}{l}-0.023 * * * \\
(0.007)\end{array}$ & $\begin{array}{l}-0.023 * * * \\
(0.007)\end{array}$ \\
\hline Rejections & $\begin{array}{l}-0.046 * * * \\
(0.004)\end{array}$ & $\begin{array}{l}-0.046 * * * \\
(0.002)\end{array}$ & $\begin{array}{l}-0.045 * * * \\
(0.004)\end{array}$ & $\begin{array}{l}-0.045 * * * \\
(0.004)\end{array}$ \\
\hline Player A & $\begin{array}{l}0.030 * * \\
(0.012)\end{array}$ & $\begin{array}{l}0.030 * * * \\
(0.008)\end{array}$ & $\begin{array}{l}0.030 * * \\
(0.012)\end{array}$ & $\begin{array}{l}0.030 * * \\
(0.012)\end{array}$ \\
\hline$I$ & & $\begin{array}{l}-0.004 \\
(0.005)\end{array}$ & $\begin{array}{l}-0.035 * * * \\
(0.011)\end{array}$ & $\begin{array}{l}-0.033 * * \\
(0.013)\end{array}$ \\
\hline$N$ & & $\begin{array}{l}-0.012 \\
(0.009)\end{array}$ & $\begin{array}{l}-0.040 * * * \\
(0.013)\end{array}$ & $\begin{array}{l}-0.032 * * \\
(0.014)\end{array}$ \\
\hline$T$ & & $\begin{array}{l}-0.003 \\
(0.009)\end{array}$ & $\begin{array}{l}-0.032 * * * \\
(0.009)\end{array}$ & $\begin{array}{l}-0.023 * * * \\
(0.007)\end{array}$ \\
\hline$P$ & & $\begin{array}{l}0.020 * * * \\
(0.007)\end{array}$ & $\begin{array}{l}-0.009 \\
(0.028)\end{array}$ & $\begin{array}{l}0.021 * * * \\
(0.006)\end{array}$ \\
\hline$I N$ & & & $\begin{array}{l}0.035 \\
(0.028)\end{array}$ & $\begin{array}{l}0.029 \\
(0.027)\end{array}$ \\
\hline$I T$ & & & $\begin{array}{l}0.040 * * * \\
(0.014)\end{array}$ & $\begin{array}{l}0.038 * * \\
(0.015)\end{array}$ \\
\hline$I P$ & & & $\begin{array}{l}0.002 \\
(0.017)\end{array}$ & \\
\hline$N T$ & & & $\begin{array}{l}0.019 \\
(0.022)\end{array}$ & $\begin{array}{l}0.025 \\
(0.019)\end{array}$ \\
\hline$N P$ & & & $\begin{array}{l}0.029 * \\
(0.017)\end{array}$ & \\
\hline
\end{tabular}


$\operatorname{adj} R^{2}$

0.423

0.424

0.425

0.425

AIC

$* * * 1 \% ; * * 5 \% ; * 10 \%$ level of significance

Standard errors in parentheses are clustered by round of play. 
Table 5: Information

(dep. var. $=$ Outcome; $N=789$ )

\begin{tabular}{|c|c|c|c|c|}
\hline & $\mathbf{I}$ & & II & \\
\hline Asymmetric & -0.018 & $(0.012)$ & -0.030 & $(0.021)$ \\
\hline$I$ & 0.001 & $(0.007)$ & $-0.035 * * *$ & $(0.006)$ \\
\hline$N$ & -0.014 & $(0.012)$ & $-0.046 * * *$ & $(0.013)$ \\
\hline$T$ & 0.001 & $(0.004)$ & $-0.035 * * *$ & $(0.007)$ \\
\hline$P$ & 0.004 & $(0.003)$ & $-0.054 * *$ & $(0.024)$ \\
\hline IN & & & $0.050 * * *$ & $(0.013)$ \\
\hline$I T$ & & & $0.053 * * *$ & $(0.006)$ \\
\hline IP & & & -0.018 & $(0.019)$ \\
\hline$N T$ & & & $-0.020 * * *$ & $(0.008)$ \\
\hline$N P$ & & & $0.069 * * *$ & $(0.011)$ \\
\hline$T P$ & & & 0.084 & $(0.037)$ \\
\hline Asym I & $-0.011 *$ & $(0.006)$ & 0.001 & $(0.013)$ \\
\hline Asym $N$ & 0.002 & $(0.016)$ & 0.011 & $(0.020)$ \\
\hline Asym $T$ & -0.009 & $(0.018)$ & 0.006 & $(0.022)$ \\
\hline Asym $P$ & $0.032 * * *$ & $(0.003)$ & $0.092 * *$ & $(0.040)$ \\
\hline Asym IN & & & -0.031 & $(0.039)$ \\
\hline Asym IT & & & $-0.024 * *$ & $(0.010)$ \\
\hline Asym IP & & & 0.038 & $(0.029)$ \\
\hline Asym NT & & & $0.078 * * *$ & $(0.015)$ \\
\hline Asym NP & & & $-0.082 * * *$ & $(0.030)$ \\
\hline Asym TP & & & -0.099 & $(0.060)$ \\
\hline $\operatorname{adj} R^{2}$ & 0.424 & & 0.429 & \\
\hline AIC & -1277.5 & & -1272.9 & \\
\hline
\end{tabular}


Table 6: Opening Offers

\begin{tabular}{|c|c|c|c|c|}
\hline specification: & 4.I & 4.II & 4.III & 5.II \\
\hline \multicolumn{5}{|c|}{ Testing Equilibrium Selection (OLS; dependent variable $=$ Opening) } \\
\hline \multirow[t]{8}{*}{ significant pers } & les: & $N$ & & $N$ \\
\hline & & & $P$ & $P$ \\
\hline & & & $N T$ & $N T$ \\
\hline & & & $N P$ & $N P$ \\
\hline & & & $T P$ & \\
\hline & & & & Asym $N$ \\
\hline & & & & Asym NP \\
\hline & & & & Asym TP \\
\hline $\operatorname{adj} R^{2}$ & 0.268 & 0.271 & 0.278 & 0.282 \\
\hline
\end{tabular}

Testing Subgame Perfection (probit; dependent variable $=$ Split)

significant personality variables:

$$
P
$$$$
\begin{aligned}
& N \\
& P
\end{aligned}
$$$$
N T
$$$$
\text { McFadden } \mathrm{R}^{2}
$$$$
0.168
$$$$
0.173
$$$$
0.160
$$$$
N
$$$$
P
$$

Asym $P$ Asym IN Asym IP Asym NT Asym NP

0.141

Testing for Non-equilibrium (probit; dependent variable $=$ Reject) significant personality variables:

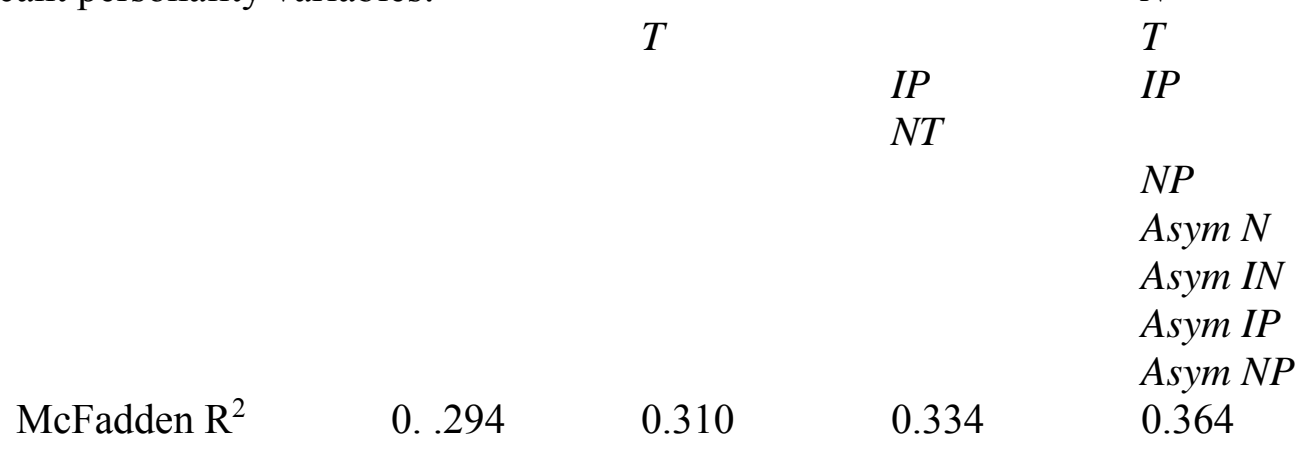

